\title{
Effects of physical environmental conditions on the patch dynamics of Dictyota pulchella and Lobophora variegata on Caribbean coral reefs
}

\author{
Henk Renken ${ }^{1}$, Peter J. Mumby ${ }^{1,2, *}$, Iakovos Matsikis ${ }^{1}$, Helen J. Edwards ${ }^{1}$ \\ ${ }^{1}$ Marine Spatial Ecology Lab, School of BioSciences, University of Exeter, Prince of Wales Road, Exeter EX4 4PS, UK \\ ${ }^{2}$ Present address: School of Biological Sciences, Goddard Building, St. Lucia Campus, University of Queensland, \\ Brisbane, Queensland 4072, Australia
}

\begin{abstract}
Trends in the percentage cover of macroalgae are generally used as an important indicator of the health of coral reefs. While considerable data exist on patterns of macroalgal cover, the underlying patch dynamics of macroalgae are poorly understood. It is important to appreciate the dynamical processes of algae because they determine the frequency and duration of competitive interaction with other taxa, such as corals, and thereby contribute to our understanding of competitive interactions. We used transition matrices to quantify and describe the patch dynamics of 2 common macroalgae in the Caribbean, Dictyota pulchella and Lobophora variegata, over a 9 mo period. Size-based matrices were constructed for both species from forereef habitats subjected to contrasting levels of wave exposure. The dynamics of $D$. pulchella are highly sensitive to the physical environment, whilst those of $L$. variegata are far less sensitive. The patch dynamics of $D$. pulchella showed a higher temporal variation than $L$. variegata, but only on the exposed forereef. $D$. pulchella virtually disappeared in January at both the exposed and sheltered sites, whereas L. variegata exhibited a continuing increase in patch size irrespective of exposure. D. pulchella formed larger, more dynamic patches under high exposure. This implies that contact interactions with coral colonies and space preemption for settling planulae will occur more frequently than in sheltered environments. Our results demonstrate the need to investigate patch dynamics of macroalgae at the individual species level, whilst taking into account environmental conditions.
\end{abstract}

KEY WORDS: Dictyota spp. $\cdot$ Lobophora variegata $\cdot$ Macroalgae $\cdot$ Patch dynamics $\cdot$ Transition matrices Resale or republication not permitted without written consent of the publisher

\section{INTRODUCTION}

Corticated foliose algae are major components of the benthic community of Caribbean coral reefs (McClanahan \& Muthiga 1998, Lirman \& Biber 2000, Beach et al. 2003) and have bloomed during the past $30 \mathrm{yr}$ (Gardner et al. 2003) for a variety of reasons. These include mass mortalities of the urchin Diadema antillarum (Carpenter 1990, Hughes 1994, McClanahan et al. 1996, Lessios et al. 2001), overfishing of herbivorous fish (Hughes 1994, McClanahan 1997, Hughes et al. 2007a), coral mortality from mass bleaching (DiazPulido \& McCook 2002, Bellwood et al. 2006) and dis- eases (Weil et al. 2006) and increasing nutrients from land-based sources (Littler et al. 1992, Lapointe et al. 1997, 2004). Although the processes driving algal dynamics have intrinsic importance, they have received renewed interest because of the deleterious consequences of algal blooms to corals (Nugues \& Bak 2006). Corticated foliose algae (Steneck \& Dethier 1994), hereafter simply referred to as macroalgae, inhibit coral recruitment through pre-emption of space (Miller \& Hay 1996) and undertake direct competitive interactions with corals (de Ruyter van Steveninck et al. 1988, Tanner 1995, Jompa \& McCook 2002a, 2003). The outcomes of such competition include a decline in coral 
recruitment (Carpenter \& Edmunds 2006, Mumby et al. 2007), a decline in growth rates of both competitors (de Ruyter van Steveninck et al. 1988, Jompa \& McCook 2002a, Nugues \& Bak 2006, Box \& Mumby 2007), a reduction in the fecundity of corals (Tanner 1995) and even coral mortality (Lewis 1986, Hughes \& Tanner 2000, Lirman 2001, Hughes et al. 2007b).

Most studies investigating the dynamics of macroalgae have used measures of abundance such as average percent cover (Lirman \& Biber 2000, Diaz-Pulido \& Garzon-Ferreira 2002). While measures of average percent cover undoubtedly have great utility and reflect patterns of abundance, they reveal little of the underlying patch dynamics, which might have important consequences for competitive interactions (Mumby et al. 2005). Competitive interactions often occur at the scale of individual patches $(\mathrm{cm})$, so a failure to appreciate the dynamic nature of such patches could obscure the cause of a competitive outcome. For example, imagine that newly-settled corals die if shaded by overgrowing algae for $1 \mathrm{wk}$ or more. A monthly survey of the average percent cover of algae in a plot finds that it remains stable and low at $10 \%$, which implies that $90 \%$ of the substratum is free of algae and suitable for settled corals to grow. However, if the patches of algae experience frequent extinction and colonisation, then much of the substratum could be covered by algae for short periods of time. In principle, the entire plot could have experienced at least 1 wk of shading, thereby preventing any corals surviving even though total algal cover remained constant over time (it merely redistributed itself over the plot in time). An observation of total coral mortality would be difficult to reconcile from the measures of overall cover but explicable by considering the patch dynamics.

Investigating patch dynamics provides insight into 2 important processes on coral reefs; contact interactions and pre-emption of space. Contact interactions between macroalgae and corals are common along the margins of coral colonies (Lirman 2001). An understanding of patch dynamics will illuminate the frequency and durations of such contacts, which may influence competitive outcomes. Macroalgae largely pre-empt space for settling corals and therefore the dynamics of algal patches may provide 'windows of opportunity' for coral settlement. A highly dynamic system, with frequent extinction and colonisation, may provide extensive settlement opportunities but also elevates the frequency of contact interactions. Thus, whether a more dynamic system favours coral recruitment depends on (1) the frequency of settlement events, and (2) the response of corals to different durations of algal contact (e.g. corals will be disadvantaged in a dynamic system if even a brief algal contact can cause mortality or retard growth).
To investigate patch dynamics, we focused on the 2 dominant macroalgae on Caribbean forereefs: Lobophora variegata (Lamouroux) and the genus Dictyota. The patches we observed were dominated by the species Dictyota pulchella (Hörnig and Schnetter), although Dictyota humifusa (Hörnig) and Dictyota pfaffii (Schnetter) were often found interwoven or under the canopy. Both Dictyota spp. and L. variegata are from the same family, Dictyotaceae, but exhibit different growth forms. D. pulchella displays a creeping interwoven to bushy growth form, usually with dichotomous branching up to $10 \mathrm{~cm}$ in height (Littler \& Littler 2000) and was the most common algae on the reef with an average overall cover of $11 \%$. L. variegata has 3 life forms - decumbent, crust, and ruffled, with distribution depending on depth, the level of grazing and habitat (Lewis et al. 1987). This study focused on the decumbent form, which has flat blades up to $15 \mathrm{~cm}$ in diameter (Littler \& Littler 2000).

We define algal patches as contiguous areas of the same species. Individual patches may grow through recruitment into the same patch or vegetative growth, and patches may fuse or divide over time. Patch dynamics are quantified using transition matrices (Caswell 2001) from changes over time in the size and number of individual patches of algae of a given species and at a given locality. We describe the patch dynamics of the predominant Caribbean macroalgae, Dictyota pulchella and Lobophora variegata, under contrasting environmental conditions and test 2 hypotheses:

$H_{1}$ : Macroalgal dynamics differ between contrasting physical environments with greater variability on more exposed (disturbed) windward systems.

$\mathrm{H}_{2}$ : Based on its branching morphology, high susceptibility to fragmentation (Herren et al. 2006a) and importance to large sparisomids as a prey item (Mumby 2006), Dictyota spp. exhibits greater temporal variation in patch dynamics than Lobophora variegata, which has a blade-like encrusting morphology and is avoided by herbivores (Paul \& Hay 1986).

\section{MATERIALS AND METHODS}

Study site. The study was undertaken on Glovers Reef $\left(16^{\circ} 50^{\prime} \mathrm{N}, 87^{\circ} 48^{\prime} \mathrm{W}\right)$, an atoll $\sim 45 \mathrm{~km}$ from the mainland of Belize. Glovers Reef presents an ideal study site as both the east and west side of the atoll (hereafter referred to as the exposed and sheltered sides, respectively) have contrasting environmental conditions. The east side is exposed to prevailing north-easterly winds (Koltes et al. 1998) and therefore has higher wave energy and rates of water flow (see also clod card data in 'Data collection' below). The 
horizontal visibility for the exposed side is approximately $25 \mathrm{~m}$ looking along a transect line at approximately $8 \mathrm{~m}$ depth, whereas on the sheltered side it rarely exceeds $10 \mathrm{~m}$ (H. Renken pers. obs.). The sheltered side only experiences moderate incident wave energy during short-term weather fronts from the northwest that occur in winter and rarely exceed $3 \mathrm{~d}$ in duration.

Data collection. Data were collected monthly from May 2005 to January 2006 (except May and October on the sheltered side, and September on both sides). Patch sizes were measured at 3 sites, each at least $500 \mathrm{~m}$ apart, on the exposed side and a further 3 sites on the sheltered side. At each site 10 permanent $0.5 \times$ $0.5 \mathrm{~m}$ quadrats were randomly placed at a depth of $8 \mathrm{~m}$. Each site was visited on a monthly basis (excluding September) and photographic video surveys made of the quadrats, which were sub-divided into four $25 \times$ $25 \mathrm{~cm}$ squares to obtain close-up images (the results of which were subsequently pooled back to each $0.25 \mathrm{~m}^{2}$ quadrat). The video camera was held perpendicular to the reef substratum at a height of $50 \mathrm{~cm}$ to avoid parallax error. The shapes of individual patches of algae were carefully delineated from the video using the software Vidana ${ }^{1}$ and their size and dynamics monitored over time. The accuracy of the method has been found to be high (Mumby et al. 2005). The percent cover for each species was also determined to obtain the monthly average percent cover for each species.

To provide an ecological context for the study, the biomass and density of herbivores were sampled at each site over the study duration using visual census. The density of scarids was sampled at each site using at least 5 replicate $30 \times 4 \mathrm{~m}$ belt transects, whilst Diadema antillarum densities were assessed on at least 4 replicate $50 \times 2 \mathrm{~m}$ belt transects. The lengths of fishes were converted to biomasses using allometric relationships from FishBase (Froese \& Pauly 2007). The differences in biomass and density were analysed using generalised linear mixed effects models with exposure and time as fixed effects and site as random effects. The identity link was used for scarid data and poisson errors used for D. antillarum counts.

Water flow was assayed using clod cards (Doty 1971). The clods were made from plaster of Paris, sun dried and glued with epoxy to plastic cards. Clods were weighed before submersion and after $48 \mathrm{~h}$ collected, air-dried and re-weighed. Up to 9 clod cards were placed randomly at the same depth $(8 \mathrm{~m})$ on each side of the atoll. Observations were repeated for July, October and January. The proportional reduction in weight loss, a measure of water flow, was arcsin trans-

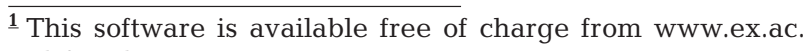
uk/msel formed and entered into a linear mixed effects model (Pinheiro \& Bates 2000) with exposure as a fixed effect and month as a random effect. Flow was significantly weaker on the sheltered side as evidenced by a significant $(p<0.01)$ negative coefficient for shelter (coefficient for sheltered -5.5 against intercept of 39.4 for the exposed side). In terms of effect size, the proportional amount of plaster dissolved in $48 \mathrm{~h}$ on the sheltered side was approximately $75 \%$ of that dissolved on the exposed side.

Transition matrices. Transition matrices divide populations into categories, usually either by age (Leslie 1945) or by life-stage (Vandermeer 1978). Entries of the matrix describe probabilities of transitions between categories in a fixed time interval. The matrix itself can be thought of as a method of describing the changes that occur in the population's structure during this time interval.

For many marine algae age is not a practical categorical variable, since it is impossible to reliably age macroalgae with the exception of large kelps (Ang \& De Wreede 1990). Furthermore, for many organisms individual age is not correlated with demographic parameters and therefore size or life stage is a better categorical variable (Sauer \& Slade 1987). In the present study we develop matrices describing transitions between different sized patches of algae.

We constructed size-based transition matrices (Caswell 2001) for each species as has been carried out in previous studies of algal dynamics (Aberg 1990). To determine appropriate size classes, we considered the frequency distribution of all patch sizes recorded during the sampling period. Patch sizes were discretized so that each size class is represented by at least 50 patches. This resulted in 7 size classes (denoted with roman numbers): (I) 0.1-0.9, (II) 1-1.9, (III) 2-3.9, (IV) 4-9.9, (V) 10-24.9, (VI) 25-49.9 and (VII) $\geq 50 \mathrm{~cm}^{2}$. We retained the small size classes because they represented the bite size of many algal herbivores (e.g. parrotfishes, Bruggemann et al. 1994), which may plausibly generate patch fragmentation. Using the Vandermeer-Moloney algorithm (Moloney 1986), we found that this size classification was a reasonable compromise between distributional and sampling errors in Lobophora variegata. A similar analysis could not be carried out reliably for Dictyota pulchella because of the large number of fragmentation and fusion events.

The transition matrix describes the contribution of each size class to every other class during a time interval $(t, t+1)$ (Table 1). The time interval used was $30 \pm$ $2 \mathrm{~d}$, which is a small enough time period to capture the fluctuations in the cover of Dictyota pulchella and Lobophora variegata (Mumby et al. 2005). Each element in the matrix represents the probability that a 
Table 1. Generic transition matrix. $\mathrm{G}_{j, i}$ denotes growth from size class $i$ to size class $j_{1}$ $F_{i}$ is the fecundity of size class $i, L_{j, i}$ is survival from size class $i$ to size class $j, C_{j, i}$ is fusion and $\mathrm{S}_{j, i}$ is fragmentation

\begin{tabular}{|l|cccccccc|}
\hline $\mathrm{t}+1$ & $\mathrm{I}$ & $\mathrm{II}$ & $\mathrm{III}$ & $\mathrm{IV}$ & $\mathrm{V}$ & $\mathrm{VI}$ & $\mathrm{VII}$ \\
\hline $\mathrm{I}$ & $\mathrm{F}_{1}+\mathrm{L}_{1,1}+\mathrm{S}_{1,1}$ & $\mathrm{~F}_{2}+\mathrm{S}_{1,2}$ & $\mathrm{~F}_{3}+\mathrm{S}_{1,3}$ & $\mathrm{~F}_{4}+\mathrm{S}_{1,4}$ & $\mathrm{~F}_{5}+\mathrm{S}_{1,5}$ & $\mathrm{~F}_{6}+\mathrm{S}_{1,6}$ & $\mathrm{~F}_{7}+\mathrm{S}_{1,7}$ \\
II & $\mathrm{G}_{2,1}+\mathrm{C}_{2,1}$ & $\mathrm{~L}_{2,2}$ & $\mathrm{~S}_{2,3}$ & $\mathrm{~S}_{2,4}$ & $\mathrm{~S}_{2,5}$ & $\mathrm{~S}_{2,6}$ & $\mathrm{~S}_{2,7}$ \\
III & $\mathrm{G}_{3,1}+\mathrm{C}_{3,1}$ & $\mathrm{G}_{3,2}+\mathrm{C}_{3,2}$ & $\mathrm{~L}_{3,3}$ & $\mathrm{~S}_{3,4}$ & $\mathrm{~S}_{3,5}$ & $\mathrm{~S}_{3,6}$ & $\mathrm{~S}_{3,7}$ \\
IV & $\mathrm{G}_{4,1}+\mathrm{C}_{4,1}$ & $\mathrm{G}_{4,2}+\mathrm{C}_{4,2}$ & $\mathrm{G}_{4,3}+\mathrm{C}_{4,3}$ & $\mathrm{~L}_{4,4}$ & $\mathrm{~S}_{4,5}$ & $\mathrm{~S}_{4,6}$ & $\mathrm{~S}_{4,7}$ \\
V & $\mathrm{G}_{5,1}+\mathrm{C}_{5,1}$ & $\mathrm{G}_{5,2}+\mathrm{C}_{5,2}$ & $\mathrm{G}_{5,3}+\mathrm{C}_{5,3}$ & $\mathrm{G}_{5,4}+\mathrm{C}_{5,4}$ & $\mathrm{~L}_{5,5}$ & $\mathrm{~S}_{5,6}$ & $\mathrm{~S}_{5,7}$ \\
VI & $\mathrm{G}_{6,1}+\mathrm{C}_{6,1}$ & $\mathrm{G}_{6,2}+\mathrm{C}_{6,2}$ & $\mathrm{G}_{6,3}+\mathrm{C}_{6,3}$ & $\mathrm{G}_{6,4}+\mathrm{C}_{6,4}$ & $\mathrm{G}_{6,5}+\mathrm{C}_{6,5}$ & $\mathrm{~L}_{6,6}$ & $\mathrm{~S}_{6,7}$ \\
VII & $\mathrm{G}_{7,1}+\mathrm{C}_{7,1}$ & $\mathrm{G}_{7,2}+\mathrm{C}_{7,2}$ & $\mathrm{G}_{7,3}+\mathrm{C}_{7,3}$ & $\mathrm{G}_{7,4}+\mathrm{C}_{7,4}$ & $\mathrm{G}_{7,5}+\mathrm{C}_{7,5}$ & $\mathrm{G}_{6,7}+\mathrm{C}_{6,7}$ & $\mathrm{~L}_{7,7}$ \\
\hline
\end{tabular}

patch in a size class will undergo a transition to another size class at time $t+1$. Elements on the diagonal of the matrix represent probabilities of remaining in the same size class during a given time interval; elements above the diagonal correspond to a reduction to smaller size classes, whereas elements below the diagonal correspond to increases to larger size classes. Where insufficient data existed for a given month, no matrices were constructed.

The rate at which algae grow may be size-dependent (Ang 1985, Ang \& De Wreede 1990). Individual patches may increase by more than 1 size class within a given period. Rapid growth of algal patches in close proximity may also cause them to fuse to form a larger patch. Algae may reduce their size (potentially returning to smaller size classes) as a result of dislodgement from waves, grazing activities of herbivores and die back after reproductive periods. We present selected matrices in the main paper to highlight dynamics of interest, but all other matrices can be found in Supplement 1 at www.int-res.com/articles/suppl/m403 p063_app.pdf.

Fragmentation and fusion of algal patches were observed to occur frequently and we devised a novel method to incorporate these demographic events into the matrices. Fragmentation is defined as the process of a patch breaking up into smaller patches, whilst fusion occurs when the fronds of neighbouring patches become indistinguishable. Fragmentation $\mathrm{S}_{j, i}$ from size class $i$ to size class $j$ (Table 1) may occur in a number of possible ways. As a simplified example, a patch in Class IV may fragment into smaller size categories as follows: I, I, I, I with a probability of $p_{1}$; I, I, II, with probability $p_{2 i}$ I, III, with probability $p_{3}$; and II, II with probability $p_{4}$. The total probability with which a member of Class IV will become a member of Class I, $\mathrm{S}_{1,4}$, is $4 p_{1}+2 p_{2}+p_{3 i}$ Class II $\mathrm{S}_{2,4}=p_{2}+2 p_{4}$ and Class III $\mathrm{S}_{3,4}=$ $p_{3}$. The probabilities $p_{x}$ are calculated as the number of events occurring out of the total number of patches in the size class that is fragmenting (Class IV in the above example).
Similarly, fusion involves several potential combinations of patches in different size classes. Fusion events, however, are more difficult to incorporate because an element of the matrix considers only the relationship between a pair of size classes, whereas the process of fusion could involve algal patches from more than 2 size classes. The fusion terms $\mathrm{C}_{j, i}$ (Table 1) are therefore not independent and the method of incorporating fusion events differs slightly to that for fragmentation. When a fusion event occurred we made the simplifying assumption that the smaller of the 2 initial patches 'died' and that the larger fused into a patch of larger size class (similar to a growth event). For example, the fusion term denoted as $\mathrm{C}_{4,3}$ results from patches in Class III fusing with patches in smaller size classes (I and II) to form a patch in Class IV.

Fusion differs from fragmentation in that the probability of patches fusing has a strong spatial dependency: 2 patches growing close together have a higher probability of fusing than 2 patches further apart. Whilst a fragmentation event involves a single patch fragmenting, fusion requires the simultaneous presence of more than one patch (of potentially different size class categories). The probability of occurrence of a given fusion event is therefore dependent upon the frequency of patches as well as upon their proximity. This makes determining the probability of occurrence difficult even for a single combination of patches, let alone for all combinations of 7 different size classes.

To simplify this problem we calculated the probability of a given fusion event for each side of the atoll by determining the total number of times that event occurred in all quadrats on that side of the atoll, thereby ignoring the instantaneous size-distribution of patches at the time of the event (which would greatly complicate the analysis). On the exposed side, we collected data from a total of 25 quadrats. Thus, the probability $\mathrm{C}_{4,3}$ will be $0.04(1 / 25)$ multiplied by the total number of times a patch of Class III fused with a smaller patch to become a patch of Class IV.

Four statistics were generated from the matrices to describe the patch population behaviour over time.

(1) Dominant eigenvalue, $\lambda_{1}$ : A population of arbitrary size structure that changes according to the transition matrix will eventually reach a stable size distribution and grow with a rate given by the dominant eigenvalue (Bierzychudek 1982), provided that the environment does not change (Caswell \& Trevisan 1994, Caswell 2001). $\lambda_{1}$ provides a single value for comparison among matrices and values of less than 1 
indicate a long term decline in the population size, whilst values greater than 1 indicate an increase in the number of patches.

(2) Damping ratio, $\rho$ : On reaching equilibrium, a population has a stable (equilibrial) size distribution. The speed of convergence to a stable size distribution is given by the ratio of the dominant eigenvalue to the second largest eigenvalue: $\lambda_{1} /\left|\lambda_{2}\right|$, known as the damping ratio ( $\rho$ ) (Caswell 2001). Convergence will be more rapid the larger $\lambda_{1}$ is relative to the other eigenvalues (Caswell 2001). The rate of convergence is independent of whether the population is in decline or growth. The damping ratio may be interpreted as a measure of the variation observed

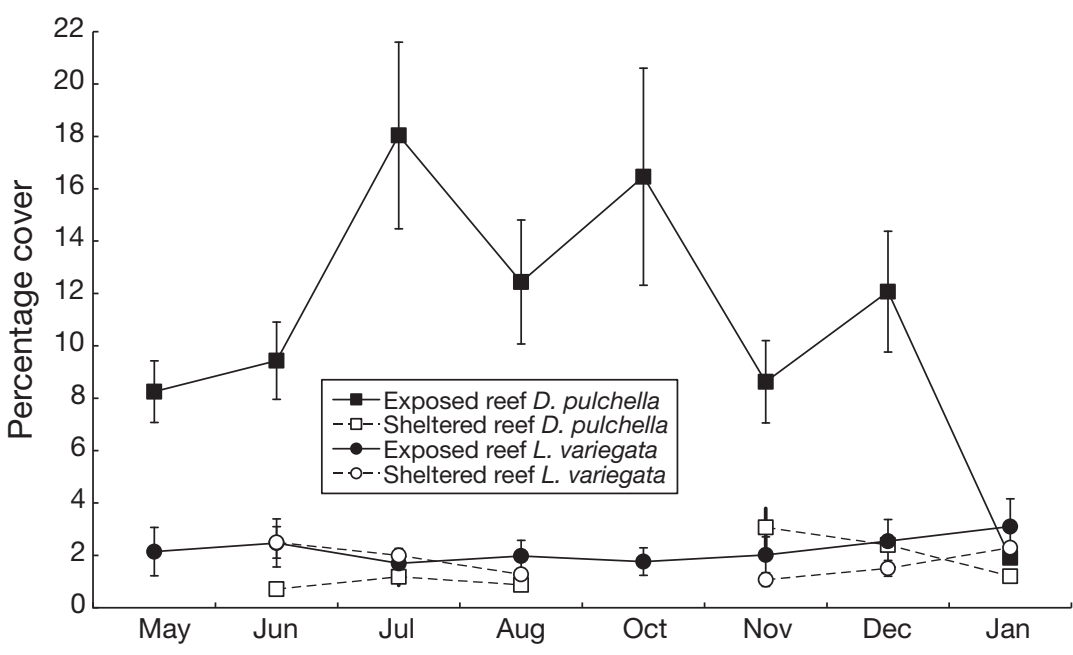

Fig. 1. Dictyota pulchella and Lobophora variegata. Percentage cover on the exposed and sheltered sides of Glovers Reef. Error bars: \pm SE within the patch dynamics because it describes the oscillations produced by the subdominant eigenvalues during convergence. A species that has a high variance in its patch dynamics due to many fusion and fragmentation events and rapid growth and shrinkage will therefore have a low damping ratio.

(3) Right eigenvector, RE: Quantifies the contribution of each size class to the total population of patches at equilibrium. Two populations can have the same dominant eigenvalue but contrasting population structure.

(4) Matrix entry ratio: Factors influencing the damping ratio in stage or size classified models are poorly understood (Caswell 2001). To aid our interpretation of the damping ratio we used a novel measure to indicate complex patch dynamics. We define the matrix entry ratio as the number of non-zero entries in the matrix divided by the total number of entries in the matrix (in this case each $7 \times 7$ matrix has 49 entries, see Table 1 ). This measure follows from the fact that species exhibiting complex patch dynamics will have more non-zero entries (probabilities of transitions) in the matrix. The maximum matrix entry ratio is 1 , corresponding to a matrix with no non-zero entries; The closer the matrix entry ratio is to 1 , the greater the variability in patch dynamics.

\section{RESULTS}

\section{Patterns of percentage cover and herbivory}

At just $2.2 \%$, the mean percentage cover of Lobophora variegata was lower than that of Dictyota pulchella
$(10.8 \%)$ on the exposed reef (Fig. 1). However the percentage covers for $D$. pulchella and $L$. variegata were similar, and consistently low, on the sheltered side of the atoll with a mean of 1.6 and $1.8 \%$, respectively (Fig. 1). On the exposed reef, the percent cover of $D$. pulchella fluctuated greatly over time from a minimum of $1.3 \%$ to a maximum of $32.3 \%$. Peaks in cover were observed in July and October. The range of fluctuations in $L$. variegata was smaller with a minimum of $0.8 \%$, a maximum of $5.4 \%$ and peaks in cover in June and January. Variation in cover was less dramatic on the sheltered side of the reef with a minimum of $0.2 \%$ and maximum of $5.4 \%$ for $D$. pulchella that occurred in November. $L$. variegata showed a minimum of $0.7 \%$ to a maximum of $3.7 \%$ with peaks in cover in June and January.

Significant differences in Diadema antillarum densities were observed, being on average $0.02 \pm 0.01 \mathrm{~m}^{-2}$ for the exposed side and $0.09 \pm 0.04 \mathrm{~m}^{-2}$ for the sheltered

Table 2. Scaridae and Diadema antillarum. Generalised linear mixed effect models for spatial and temporal patterns in the density of $D$. antillarum and biomass of scarids at Glovers Reef Atoll. Significant results indicated in bold.

Reference data were exposed reefs in August. nd = no data

\begin{tabular}{|c|c|c|c|c|c|c|}
\hline \multirow[t]{2}{*}{ Factor } & \multicolumn{3}{|c|}{ D. antillarum } & \multicolumn{2}{|c|}{ Scaridae } & \multirow[b]{2}{*}{$t$} \\
\hline & Coefficient & SE & $\mathrm{p}$ & Coefficient & $\mathrm{SE}$ & \\
\hline Intercept & 0.35 & 0.13 & 0.007 & 1388 & 153 & 9.07 \\
\hline Sheltered & 1.72 & 0.10 & $<0.0001$ & -87 & 154 & -0.57 \\
\hline December & -0.04 & 0.11 & 0.69 & -260 & 149 & -1.74 \\
\hline January & 0.70 & 0.13 & $<0.0001$ & 359 & 175 & 2.05 \\
\hline July & 0.05 & 0.12 & 0.67 & 153 & 280 & 0.55 \\
\hline June & nd & nd & nd & 23 & 175 & 0.13 \\
\hline November & 0.13 & 0.12 & 0.25 & -483 & 152 & -3.18 \\
\hline October & 0.16 & 0.23 & 0.46 & -422 & 214 & -1.96 \\
\hline
\end{tabular}




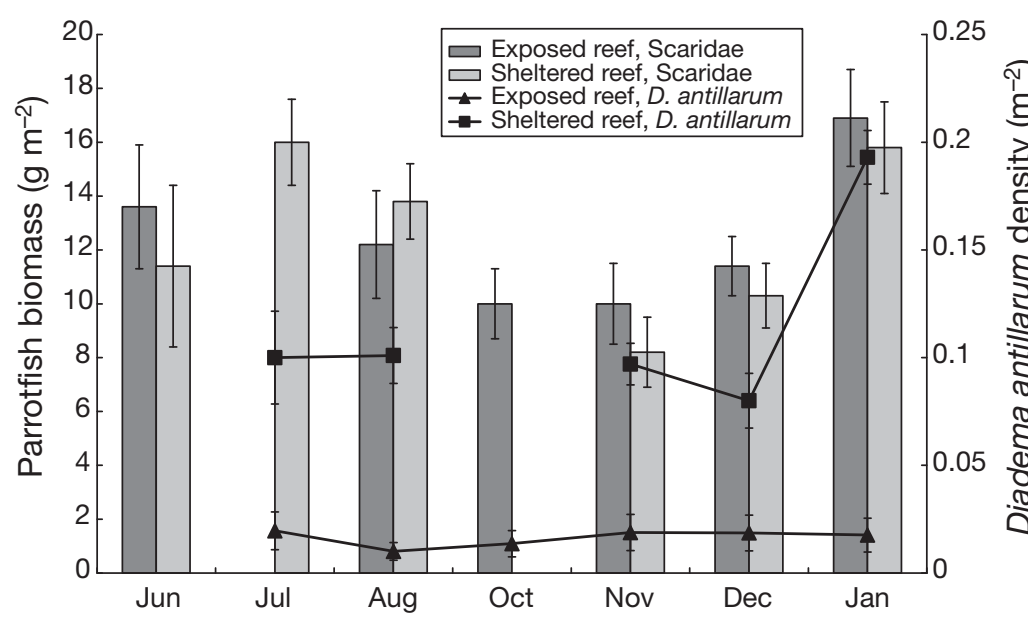

Fig. 2. Scaridae and Diadema antillarum. Parrotfish biomass and D. antillarum densities from June 2005 to January 2006. Left axis: Bars. Right axis: Lines and symbols. Error bars: $\pm \mathrm{SE}$

side (Table 2, Fig. 2). However, no significant difference in scarid biomass was observed across the atoll, although biomass did vary over time (Table 2, Fig. 2).

\section{Growth rates and size structure of populations $\left(\lambda_{1}\right)$}

All algal populations fell on a trajectory of long-term population growth from May to November, after which the trajectory reversed to one of decline during December and January with $\lambda_{1}<1$ (Table 3 ). The effect of exposure on the size distribution of patches differed among species. In Dictyota pulchella, the equilibrial size distribution of patches in summer was dominated by large patches (Classes V to VII) on the exposed side whereas small patches dominated the sheltered side (Classes I and II; Table 3). In contrast, the effect of exposure on the size distribution of patches was minor in Lobophora variegata with a relatively weak shift in size distribution in July only (Table 3). The sudden decline in population growth rate in December to Jan- uary occurred in both algal species but in very different ways. In $D$. pulchella, the population reversed from one dominated by large patches towards one dominated by small patches (Class I). While the overall population size of L.variegata was set to decline in this winter period, this actually resulted from a shift towards fewer, but larger, patches (Table 3) and was accompanied by a rise in cover (Fig. 1).

\section{Dynamics of Dictyota pulchella and Lobophora variegata under varying environmental conditions}

Comparison of the matrices for Dictyota pulchella on the exposed and sheltered sides of the atoll reveals marked differences (Table 4). On the exposed side $D$. pulchella grew to the largest size class category (VII), whereas patches never grew larger than Class $\mathrm{V}$ on the sheltered side. For the period June-July on the sheltered reef $D$. pulchella patches increased in size, changing from a maximum size category of Class III to Class IV. Again, patches were larger on the exposed reef as the maximum size class (VII) had already been reached by July on this side of the atoll. D. pulchella also exhibited a reef-wide decline in average patch size in December to January when the majority of patches were restricted to Classes I and II.

Unlike Dictyota pulchella, patch population growth rates in Lobophora variegata did not vary consistently with exposure (Table 4). The maximum size of patches on the exposed reef declined from May-June (Class VII) to August (Class V) and then increased to include Class VII by January (see Table S7 in Supplement 1). The latter increase was also observed on the sheltered reef, but to a lesser extent. The most striking difference between the algal species occurred in the period December to January; whilst D. pulchella showed a

Table 3. Dictyota pulchella and Lobophora variegata. Growth rates (dominant eigenvalue $\lambda_{1}$ ) and dominant size structure of algal populations (right eigenvector, RE). nd = no data. RE denotes percentage of all patches found in a size class and is given for the dominant size classes (roman numerals, see Table 4 for definitions) only

\begin{tabular}{|c|c|c|c|c|c|c|c|c|}
\hline \multirow[t]{2}{*}{ Months } & \multicolumn{4}{|c|}{$\longrightarrow$ D. pulchella } & \multicolumn{3}{|c|}{$\longrightarrow$ L. variegata } & \multirow{2}{*}{$\begin{array}{l}\text { Sheltered } \\
\text { RE (\%) }\end{array}$} \\
\hline & $\lambda_{1}$ & $\begin{array}{l}\text { Exposed } \\
\text { RE }(\%)\end{array}$ & $\lambda_{1}$ & $\begin{array}{l}\text { RE }(\%) \\
\text { leltered }\end{array}$ & $\lambda_{1}$ & $\begin{array}{l}\text { RE }(\%) \\
\text { RE }\end{array}$ & $\lambda_{1}$ & \\
\hline May-June & 1.03 & V 32, VI 17 & nd & nd & 1.00 & IV 27, III 24 & nd & nd \\
\hline June-July & 1.07 & VII 80 & 1.74 & I 76 & 1.07 & I 47, II 26 & 1.11 & I 50, II 30 \\
\hline July-August & 1.06 & V 31, VI 13 & 1.10 & II 45, I 22 & 1.14 & IV 34, III 30 & 1.18 & I 54, II 21 \\
\hline Oct-Nov & 1.07 & IV 31, V 21 & nd & nd & 1.04 & IV 43, III 23 & nd & nd \\
\hline Nov-Dec & 1.19 & VII 41, V 22 & 1.06 & II 45, III 23 & 1.07 & IV 37, III 21 & 1.01 & III 33, IV 31 \\
\hline Dec-Jan & 0.67 & I 87 & 0.83 & I 89 & 0.89 & V 37, VI 26 & 0.81 & IV 46, V 27 \\
\hline
\end{tabular}


Table 4. Dictyota pulchella and Lobophora variegata. Transition matrices for selected time periods. Roman numbers indicate size classes, I $\left(0-0.9 \mathrm{~cm}^{2}\right)$, II $\left(1-1.9 \mathrm{~cm}^{2}\right)$, III $\left(2-3.9 \mathrm{~cm}^{2}\right)$, IV $\left(4-9.9 \mathrm{~cm}^{2}\right), \mathrm{V}\left(10-24.9 \mathrm{~cm}^{2}\right)$, VI $\left(25-49.9 \mathrm{~cm}^{2}\right)$, VII $\left(\geq 50 \mathrm{~cm}^{2}\right) .---:$ no entries for the particular matrix

\begin{tabular}{|c|c|c|c|c|c|c|c|c|c|c|c|c|c|c|c|c|}
\hline & \multicolumn{8}{|c|}{ Exposed side } & & \multicolumn{6}{|c|}{ June } & \\
\hline & & $\mathbf{I}$ & II & III & IV & $\mathbf{V}$ & VI & VII & & $\mathbf{I}$ & II & III & IV & $\mathbf{V}$ & VI & VII \\
\hline J & I & 0.50 & 0.22 & 0.09 & 0.02 & --- & --- & --- & I & 0.79 & 0.33 & 0.23 & 0.04 & 0.07 & 0.33 & --- \\
\hline u & II & 0.40 & 0.35 & 0.20 & 0.11 & 0.02 & --- & --- & II & 0.26 & 0.38 & 0.19 & 0.17 & --- & 0.33 & --- \\
\hline 1 & III & 0.20 & 0.32 & 0.31 & 0.24 & 0.02 & --- & --- & III & 0.10 & 0.22 & 0.31 & 0.32 & 0.23 & 0.33 & --- \\
\hline y & IV & 0.10 & 0.05 & 0.21 & 0.33 & 0.15 & --- & --- & IV & 0.05 & 0.05 & 0.11 & 0.39 & 0.38 & 0.66 & 0.50 \\
\hline & $\mathbf{V}$ & --- & 0.02 & 0.14 & 0.20 & 0.51 & 0.07 & --- & $\mathbf{V}$ & --- & --- & $\begin{array}{ll}-- \\
\end{array}$ & --- & 0.46 & 0.33 & 0.50 \\
\hline & VI & --- & --- & 0.04 & 0.02 & 0.17 & 0.07 & 0.13 & VI & --- & --- & --- & --- & --- & 0.33 & --- \\
\hline & VII & --- & --- & --- & 0.08 & 0.08 & 0.85 & 0.95 & VII & --- & --- & --- & --- & --- & --- & $-\cdots$ \\
\hline \multirow{9}{*}{$\begin{array}{l}\mathbf{J} \\
\mathbf{a} \\
\mathbf{n} \\
\mathbf{u} \\
\mathbf{a} \\
\mathbf{r} \\
\mathbf{y}\end{array}$} & \multicolumn{8}{|c|}{ December } & \multicolumn{8}{|c|}{ December } \\
\hline & & $\mathbf{I}$ & II & III & IV & $\mathbf{V}$ & VI & VII & & $\mathbf{I}$ & II & III & IV & $\mathbf{V}$ & VI & VII \\
\hline & I & 0.60 & 0.47 & 0.52 & 0.21 & 0.18 & 0.19 & 0.42 & I & 0.24 & --- & --- & 0.02 & --- & --- & --- \\
\hline & II & 0.07 & 0.21 & 0.24 & 0.47 & 0.31 & 0.39 & 0.89 & II & 0.19 & 0.05 & 0.12 & 0.02 & --- & --- & --- \\
\hline & III & --- & --- & 0.03 & 0.13 & 0.39 & 0.36 & 0.79 & III & 0.05 & 0.26 & 0.18 & 0.08 & 0.06 & --- & --- \\
\hline & IV & --- & --- & --- & 0.06 & 0.11 & 0.12 & 0.32 & IV & --- & 0.20 & 0.38 & 0.54 & 0.06 & --- & --- \\
\hline & $\mathbf{V}$ & --- & --- & --- & --- & 0.01 & 0.03 & 0.16 & $\mathbf{V}$ & --- & --- & 0.16 & 0.47 & 0.72 & --- & --- \\
\hline & VI & --- & --- & --- & --- & --- & --- & --- & VI & --- & --- & 0.14 & 0.02 & 0.24 & 0.50 & --- \\
\hline & VII & --- & --- & --- & --- & --- & --- & --- & VII & --- & --- & --- & --- & 0.10 & 0.54 & --- \\
\hline \multicolumn{17}{|c|}{ Sheltered side } \\
\hline $\mathbf{J}$ & & I & II & III & IV & $\mathbf{V}$ & VI & VII & & I & II & III & IV & $\mathbf{V}$ & VI & VII \\
\hline $\mathbf{u}$ & I & 1.61 & 0.44 & 0.33 & --- & --- & -- & --- & I & 0.90 & 0.24 & 0.14 & 0.13 & --- & --- & --- \\
\hline 1 & II & 0.25 & 0.39 & 0.44 & --- & --- & --- & --- & II & 0.36 & 0.36 & 0.33 & 0.15 & 0.21 & --- & --- \\
\hline y & III & 0.11 & 0.22 & 0.17 & --- & --- & --- & --- & III & --- & 0.12 & 0.28 & 0.38 & 0.07 & 0.40 & --- \\
\hline & IV & --- & --- & --- & --- & --- & --- & --- & IV & 0.09 & 0.08 & 0.04 & 0.41 & 0.29 & 0.20 & --- \\
\hline & V & --- & --- & --- & --- & --- & --- & --- & V & --- & --- & --- & --- & 0.33 & 0.40 & --- \\
\hline & VI & --- & --- & --- & --- & --- & --- & --- & VI & --- & --- & --- & --- & --- & --- & --- \\
\hline & VII & --- & --- & --- & --- & --- & --- & --- & VII & --- & --- & --- & --- & --- & --- & --- \\
\hline \multirow{9}{*}{$\begin{array}{l}\mathbf{J} \\
\mathbf{a} \\
\mathbf{n} \\
\mathbf{u} \\
\mathbf{a} \\
\mathbf{r} \\
\mathbf{y}\end{array}$} & \multicolumn{8}{|c|}{ December } & \multicolumn{8}{|c|}{ December } \\
\hline & & I & II & III & IV & $\mathbf{V}$ & VI & VII & & I & II & III & IV & V & VI & VII \\
\hline & I & 0.79 & 0.40 & 0.24 & 0.23 & 0.17 & --- & --- & I & 0.47 & 0.12 & --- & --- & --- & --- & --- \\
\hline & II & 0.07 & 0.17 & 0.35 & 0.41 & 0.17 & --- & --- & II & 0.41 & 0.21 & 0.07 & --- & --- & --- & --- \\
\hline & III & $\begin{array}{l}-- \\
\end{array}$ & 0.05 & 0.22 & 0.27 & 0.33 & --- & --- & III & 0.17 & 0.24 & 0.54 & 0.03 & +-- & --- & --- \\
\hline & IV & --- & --- & 0.05 & 0.09 & 0.33 & --- & --- & IV & 0.03 & 0.12 & 0.36 & 0.67 & 0.14 & --- & --- \\
\hline & $\mathrm{V}$ & $\begin{array}{ll}-- \\
\end{array}$ & --- & $\begin{array}{l}-- \\
\end{array}$ & --- & --- & --- & --- & $\mathrm{V}$ & --- & 0.09 & 0.02 & 0.39 & 0.14 & $\begin{array}{l}-- \\
\end{array}$ & --- \\
\hline & VI & --- & --- & --- & --- & --- & --- & --- & VI & --- & --- & --- & --- & 0.55 & --- & --- \\
\hline & VII & --- & --- & --- & --- & --- & --- & --- & VII & --- & --- & --- & --- & --- & --- & $-\cdots$ \\
\hline
\end{tabular}

rapid decline in patch sizes, L. variegata patches continued to grow into the larger size categories reaching Classes VI and VII.

\section{Temporal variation in patch dynamics}

Both metrics of temporal variation in patch dynamics, damping ratios and matrix entry ratios (Fig. 3), suggested that variation was greatest under high wave exposure in Dictyota pulchella Specifically, damping ratios for $D$. pulchella on the exposed reef were generally less than those of the sheltered reef, with the exception of the die-back event in December-January (Fig. 3). Similarly, the matrix entry ratio was generally greater on the exposed side, varying from 0.50 to 0.81 on the exposed side to 0.43 to 0.54 on the sheltered side.

Temporal and indeed spatial variation in dynamics were considerably lower in Lobophora variegata than Dictyota pulchella (Fig. 3). For example, the coefficient of variation in damping ratio across sites and seasons was double the level in D. pulchella than was found in L. variegata (0.52 vs. 0.26 , respectively). This pattern was even more marked in the coefficient of variation of matrix entry ratio which was nearly an order of magni- 
tude lower in L. variegata (0.05 vs. 0.2 for D. pulchella). The overall variation in damping ratio in $L$. variegata was lower than that of $D$. pulchella (coefficient of variation across months and reefs 0.25 in $L$. variegata yet double that value in $D$. pulchella 0.52 ). Thus, not only was $L$. variegata more stable over time, but also differences in dynamics across the atoll were minor.

The number of fragmentation and fusion events in Dictyota pulchella were much greater on the exposed side of the atoll: 68 fragmentation and 42 fusion events (exposed) versus 5 and 0 events (sheltered) respectively (Table 5). Exposure-based differences in fragmentation and fusion were less marked in Lobophora variegata (Table 5): fragmentation and fusion events occurred 18 and 37 times for the exposed and 4 and 17 for the sheltered sides respectively. A striking difference between the 2 algal species was found in that fragmentation events outnumbered the fusion events in D. pulchella whilst the opposite pattern occurred in L. variegata.

The large number of fragmentation events in Dictyota pulchella allowed the relationship to be plotted between patch size and fragmentation rate on exposed reefs. Fragmentation rate was a linear positive function of patch size (Fig. 4, fragmentation rate $=1.53+0.42 \times$ patch size, $r^{2}=0.99$ ).
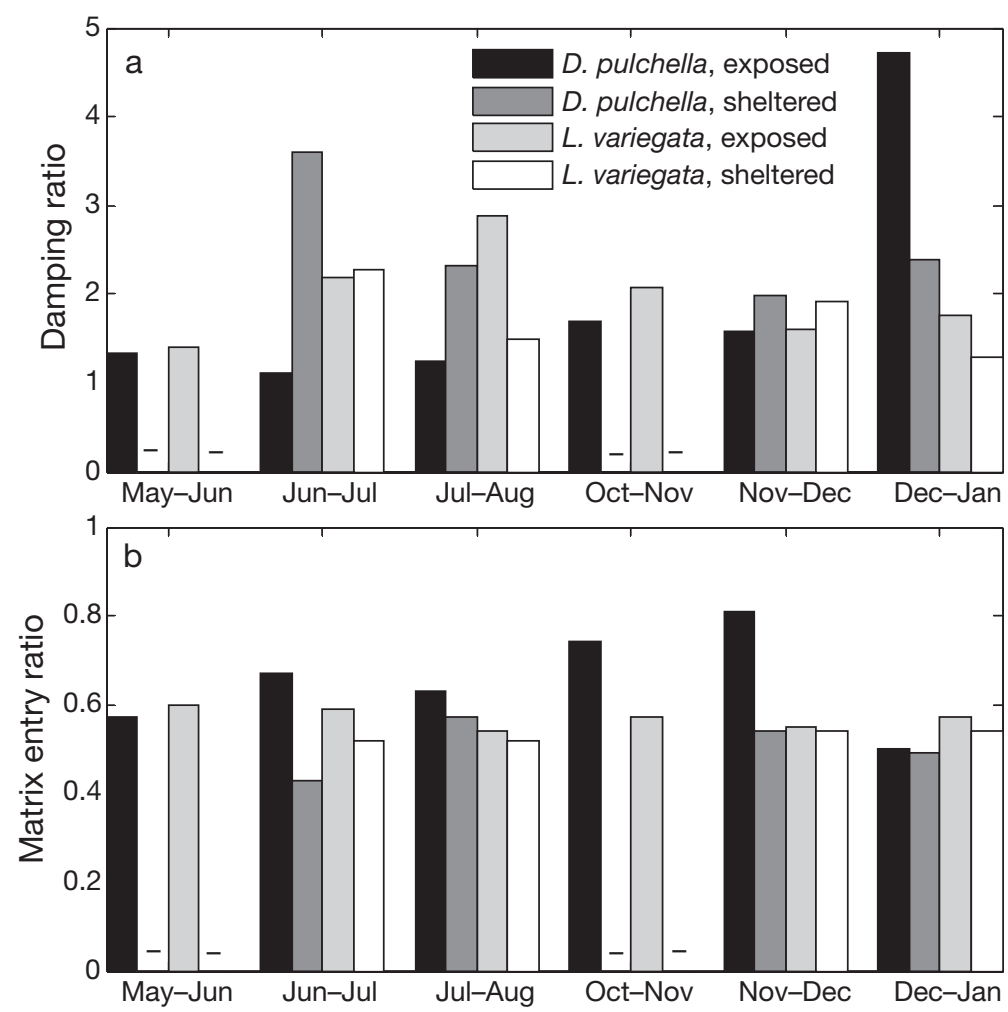

Fig. 3. Dictyota pulchella and Lobophora variegata. Seasonal patterns in the (a) damping ratio, and (b) matrix entry ratio under 2 levels of wave exposure. (-) no data

\section{Influence of fusion and fragmentation events on growth rates and damping ratios}

To gain insight into the importance of considering fusion and fragmentation, matrices were compared both with and without these processes. For both algal species, exclusion of fragmentation and fusion resulted in both the dominant eigenvalue and damping ratio being reduced (see Tables S4 \& S10 in Supplement 1). In Dictyota pulchella the dominant eigenvalue was reduced from 1.07 to 0.99 and for Lobophora variegata it was reduced from 1.04 to 0.98 . The damping ratio in D. pulchella was reduced from 1.70 to 1.59 and in $L$. variegata it declined from 2.08 to 1.95 . Therefore, in the absence of explicit incorporation of fragmentation and fusion events, population behaviour of both species shifted from net growth to net decline.

\section{DISCUSSION}

\section{Patterns of cover and population growth rates of Dictyota pulchella and Lobophora variegata}

Patterns of overall percentage cover in space and time can mask important differences in the underlying patch-level dynamics of algal species. For example, a decline in cover of Dictyota pulchella was observed on the exposed side of the atoll from October to November although growth rates generated using transition matrices indicate an increase in the population. This discrepancy can be explained by the fact that a population may be increasing in size (number of patches) even though the patches themselves are becoming smaller (which would be recorded as a reduction in cover).

The most striking difference in patch dynamics between the 2 algal species was found in December to January. During these months Dictyota pulchella patches showed a rapid decline in size, whilst Lobophora variegata patches continued to grow. The decline in the size of patches of D. pulchella was observed on both sides of the atoll which might indicate a life historyrelated event, such as sexual reproduction, rather than an environmental cause. Studies of D. pulchella have shown periodicity in sexual reproduction (Lewis 1910, Hoyt 1927), with gamete production related to tidal levels on fortnightly or monthly intervals, but this does not necessary correlate with changes in the season (Neto 2000). 
Table 5. Dictyota pulchella and Lobophora variegata. Fragmentation and fusion events on exposed versus sheltered sides of a reef. Frag. = fragmentation event, fus. $=$ fusion event

\begin{tabular}{|c|c|c|c|c|c|c|c|c|}
\hline \multirow[b]{2}{*}{ Interval } & \multicolumn{4}{|c|}{$\longrightarrow$ Dictyota spp. -} & \multicolumn{4}{|c|}{- L. variegata } \\
\hline & $\begin{array}{c}\text { Expose } \\
\text { Frag. }\end{array}$ & $\begin{array}{l}\text { d reef } \\
\text { Fus. }\end{array}$ & $\begin{array}{r}\text { Shelter } \\
\text { Frag. }\end{array}$ & $\begin{array}{c}\text { d reef } \\
\text { Fus. }\end{array}$ & $\begin{array}{r}\text { Expose } \\
\text { Frag. }\end{array}$ & $\begin{array}{l}\text { d reef } \\
\text { Fus. }\end{array}$ & $\begin{array}{c}\text { Sheltere } \\
\text { Frag. }\end{array}$ & $\begin{array}{c}\text { ed reef } \\
\text { Fus. }\end{array}$ \\
\hline June & 2 & 0 & 0 & 0 & 0 & 2 & 0 & 0 \\
\hline July & 3 & 9 & 0 & 0 & 3 & 1 & 2 & 2 \\
\hline August & 9 & 0 & 0 & 0 & 3 & 4 & 1 & 1 \\
\hline November & 39 & 9 & 0 & 0 & 4 & 8 & 0 & 0 \\
\hline December & 7 & 24 & 3 & 0 & 7 & 5 & 1 & 3 \\
\hline January & 18 & 0 & 2 & 0 & 1 & 17 & 0 & 11 \\
\hline Total & 68 & 42 & 5 & 0 & 18 & 37 & 4 & 17 \\
\hline
\end{tabular}

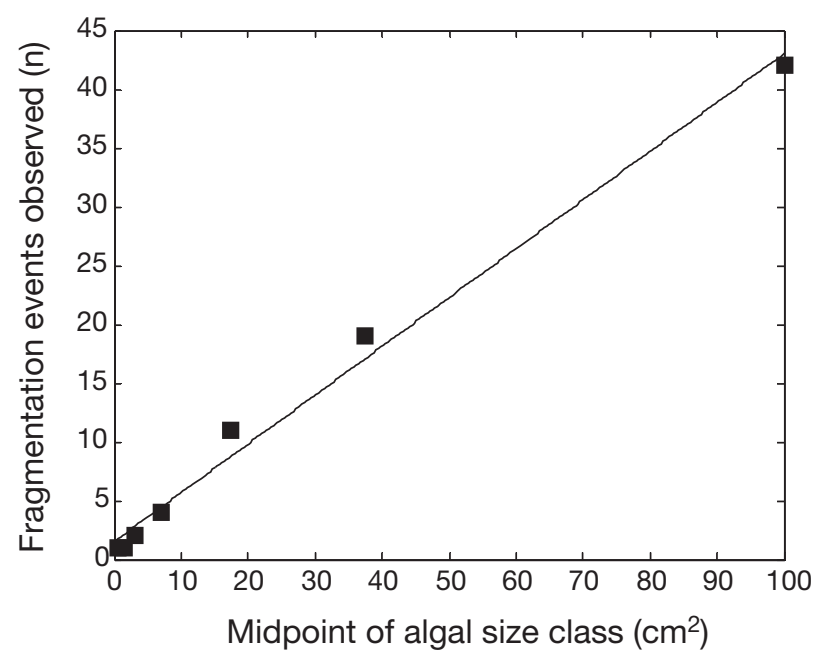

Fig. 4. Dictyota pulchella. Effect of patch size on the fragmentation rate from May to January under high wave exposure

However, a study of Dictyota dichotoma (Hudson) suggested that individual algae may survive winter months by remaining at an early developmental stage (Richardson 1979).

As we did not survey throughout an entire year, we cannot ascertain whether Lobophora variegata exhibits the dramatic die-back observed in Dictyota pulchella. While the transition matrices and percentage cover data do imply a reduction in the maximum sizes of patches to a minimum in August, previous studies of L. variegata on dead coral substrate found no evidence of seasonal die-backs in Belize (Mumby et al. 2005) and studies in North Carolina observed an increase in L. variegata cover for almost 2 yr before a significant reduction took place (Peckol \& Searles 1984). In Curacao, no evidence was found for seasonality in $L$. variegata (de Ruyter van Steveninck \& Breeman 1987). However, L. variegata did show seasonal variation in size and reproductive status in Mexico, but this was not related to cover or dynamics and was measured in a very different, shallow habitat (Quan-Young et al. 2004).

\section{$H_{1}$ : Macroalgal dynamics differ be- tween contrasting physical environ- ments with greater variability on more exposed (disturbed) windward systems}

We accept the hypothesis that the environment has a strong influence on the patch dynamics of Dictyota pulchella, but data from the transition matrices does not support this hypothesis for Lobophora variegata. Under exposed conditions, D. pulchella reaches large patch sizes (Class VII versus Class IV under sheltered conditions) and has more variable dynamics as evidenced by the high rates of fragmentation and fusion and by the metrics of temporal variation (damping ratio and matrix entry ratio). Previous studies have used temporal variation in some physical factors (temperature, nutrient supply, light intensity and water motion) to explain seasonal patterns of reef algal abundance (Chapman 1974, Ateweberhan et al. 2005), but the importance of these processes in driving patch dynamics has received little attention. Here we have found significant spatial variation in the dynamics of $D$. pulchella spp., which are strongly associated with exposure. The specific mechanisms responsible for these exposure-based patterns are not yet clear. Both nutrient flux and light intensity have a strong influence on algal growth rates and the combination of these factors may determine maximum coral reef algal production (Carpenter 1985, Steneck \& Dethier 1994, Creed et al. 1997). Although background dissolved inorganic nitrate, ammonium and phosphate concentrations are similar on both sides of the atoll (McClanahan et al. 2004), higher water flow rates on the exposed side will increase nutrient flux (Carpenter \& Williams 2007) and are likely to have fostered higher productivity. D. pulchella may also have been light limited on the sheltered side where wind-driven sediment transport reduces light penetration throughout most of the year (Gischler 1994). A recent study found that Dictyota menstrualis was light limited, but only at depths of over $32 \mathrm{~m}$ (Beach et al. 2006). In shallower but more turbid water this may be a possible mechanism causing a reduction in productivity.

Recent studies have shown that members of the genus Dictyota can successfully reproduce through vegetative fragmentation (Beach et al. 2003, Herren et al. 2006b). Fragments, generated mainly by the grazing activities of fish, have the ability to re-attach within $24 \mathrm{~h}$ in the field (Herren et al. 2006b). Higher water flow rates found on the exposed side may have facilitated the spread of these fragments and thus enabled Dictyota pulchella to colonise available space rapidly. 
The process (or processes) that generate fragments appear to be a linear function of patch size. This might occur, for example, if sparisomid parrotfish fed randomly from patches of $D$. pulchella rather than exhibiting a preference for particular size classes (a hypothesis we will test in future).

The observed lack of response to the environment by Lobophora variegata is difficult to explain. Whilst being a relatively unpalatable alga (Paul \& Hay 1986), several studies have documented biomass removal by herbivores (de Ruyter van Steveninck et al. 1988, Jompa \& McCook 2002b). However, scarid biomass was not significantly different between the exposed and sheltered sides. Whilst Diadema antillarum densities were significantly different between the 2 sides of the atoll, they remain low $\left(\ll 1 \mathrm{~m}^{-2}\right)$ and it is doubtful that densities are high enough to control macroalgal cover. Morphological variability in response to different environmental conditions is a common phenomenon in seaweeds (Norton et al. 1982, Fowler-Walker et al. 2006) so it is feasible that subtle morphological adaptations enable the alga to maintain growth in quite different physical environments.

\section{$\mathrm{H}_{2}$ : Based on its branching morphology and high susceptibility to fragmentation, Dictyota pulchella exhibits greater temporal variation in patch dynamics than Lobophora variegata}

Our evidence supports the hypothesis that Dictyota pulchella exhibits higher temporal variation in its patch dynamics than Lobophora variegata, but only on the exposed side of the atoll. Fragmentation events are a major cause of the high temporal variance in D. pulchella dynamics and these occur more frequently on the exposed side of the atoll (68 events as opposed to 5). The cause of higher fragmentation is not clear but could involve a higher feeding rate on macroalgae by herbivorous fish or greater rates of wave-induced algal dislodgement. Increased rates of fusion will also contribute to more variable dynamics and fusion rates are also likely to be greater on the exposed reef because of high primary production, which increases the growth rate of individual patches. L. variegata showed the opposite trend in that fusion rates exceeded fragmentation irrespective of exposure. A plausible explanation for this might be that L. variegata, being a less palatable species (Paul \& Hay 1986), is less likely to be disturbed by grazers resulting in less fragmentation. The higher number of fusion events may be partly explained by the limited dispersal range of the species (De Ruyter van Steveninck \& Breeman 1987) and thus newly-formed patches will grow relatively close together, thereby increasing the chance of fusion.
In conclusion, we provide evidence that for Dictyota pulchella the environment in which it grows plays an important role in its patch dynamics and demography. In contrast, the environment displayed a remarkable lack of influence on the patch dynamics and demography of Lobophora variegata, which is observed to perform equally well under varying conditions. Unraveling these subtleties in the patch dynamics of both species requires further exploration of the transition matrices and experimental studies to test specific hypothesis on sexual reproduction and morphological adaptability.

Acknowledgements. We are grateful to E. Husain for help with data collection and the staff of Glover's Reef Marine Research Station for logistical support and data collection. We thank D. Hodgson for useful comments during development of this paper. Funding was provided by the Wildlife Conservation Society, the National Geographic Society and NERC. We thank 3 referees for helpful comments on an early draft of the paper.

\section{LITERATURE CITED}

Åberg P (1990) Measuring size and choosing category size for a transition matrix study of the seaweed Ascophyllum nodosum. Mar Ecol Prog Ser 63:281-287

Ang PO (1985) Phenology of Sargassum siliquosum and S. paniculatum (Sargassaceae, Phaeophyta) in the reef flat of Balibago (Calatagan, Philippines). Proc 5th Int Coral Reef Symp, Tahiti 5:51-57

> Ang PO Jr, De Wreede RE (1990) Matrix models for algal life history stages. Mar Ecol Prog Ser 59:171-181

Ateweberhan M, Bruggemann JH, Breeman AM (2005) Seasonal patterns of biomass, growth and reproduction in Dictyota cervicornis and Stoechospermum polypodioides (Dictyotales, Phaeophyta) on a shallow reef flat in the southern Red Sea (Eritrea). Bot Mar 48:8-17

Beach K, Walters L, Borgeas H, Smith C, Coyer J, Vroom P (2003) The impact of Dictyota spp. on Halimeda populations of conch reef, Florida Keys. J Exp Mar Biol Ecol 297: 141-159

> Beach KS, Walters LJ, Borgeas HB (2006) Irradiance and nutrient limitation of Dictyota spp. populations on conch reef, Florida Keys, USA. J Exp Mar Biol Ecol 329:101-112

> Bellwood DR, Hoey AS, Ackerman JL, Depczynski M (2006) Coral bleaching, reef fish community phase shifts and the resilience of coral reefs. Glob Change Biol 12:1587-1594

Bierzychudek P (1982) The demography of jack-in-the-pulpit, a forest perennial that changes sex. Ecol Monogr 52: 335-351

Box SJ, Mumby PJ (2007) Effect of macroalgal competition on growth and survival of juvenile Caribbean corals. Mar Ecol Prog Ser 342:139-149

Bruggemann JH, van Oppen MJH, Breeman AM (1994) Foraging by the stoplight parrotfish Sparisoma viride. I. Food selection in different socially determined habitats. Mar Ecol Prog Ser 106:41-55

Carpenter R (1985) Relationships between primary production and irradiance in coral reef algal communities. Limnol Oceanogr 30:784-793

Carpenter RC (1990) Mass mortality of Diadema antillarum. I. Long-term effects on sea urchin population-dynamics and coral reef algal communities. Mar Biol 104:67-77 
Carpenter RC, Edmunds PJ (2006) Local and regional scale recovery of Diadema promotes recruitment of scleractinian corals. Ecol Lett 9:271-280

Carpenter RC, Williams SL (2007) Mass transfer limitation of photosynthesis of coral reef algal turfs. Mar Biol 151: $435-450$

Caswell H (2001) Matrix population models. Sinauer Associates, Sunderland

Caswell H, Trevisan MC (1994) Sensitivity analysis of periodic matrix models. Ecology 75:1299-1303

> Chapman ARO (1974) The ecology of macroscopic marine algae. Annu Rev Ecol Syst 5:65-80

> Creed JC, Norton TA, Kain JM (1997) Intraspecific competition in Fucus serratus germlings: the interaction of light, nutrients and density. J Exp Mar Biol Ecol 212:211-223

> de Ruyter van Steveninck ED, Breeman AM (1987) Deep water populations of Lobophora variegata (Phaeophyceae) on the coral reef of Curaçao: influence of grazing and dispersal on distribution patterns. Mar Ecol Prog Ser 38:241-250

de Ruyter van Steveninck ED, Mulekom LL, Breeman AM (1988) Growth inhibition of Lobophora variegata (Lamouroux) Womersley by scleractinian corals. J Exp Mar Biol Ecol 115:169-178

> Diaz-Pulido G, Garzon-Ferreira J (2002) Seasonality in algal assemblages on upwelling-influenced coral reefs in the Colombian Caribbean. Bot Mar 45:284-292

Diaz-Pulido G, McCook LJ (2002) The fate of bleached corals: patterns and dynamics of algal recruitment. Mar Ecol Prog Ser 232:115-128

> Doty MS (1971) Measurement of water movement in reference to benthic algal growth. Bot Mar 14:32-35

Fowler-Walker MJ, Wernberg T, Connell SD (2006) Differences in kelp morphology between wave sheltered and exposed localities: morphologically plastic or fixed traits? Mar Biol 148:755-767

Froese R, Pauly D (eds) (2007) FishBase. www.fishbase.org

Gardner TA, Cote IM, Gill JA, Grant A, Watkinson AR (2003) Long-term region-wide declines in Caribbean corals. Science 301:958-960

Gischler E (1994) Sedimentation on three Caribbean atolls: Glovers Reef, Lighthouse Reef and Turneffe Islands, Belize. Facies 31:243-254

Herren LW, Walters LJ, Beach KS (2006a) Fragment generation, survival, and attachment of Dictyota spp. at Conch Reef in the Florida Keys, USA. Coral Reefs 25:287-295

Herren LW, Walters LJ, Beach KS (2006b) Fragment generation, survival, and attachment of Dictyota spp. at Conch Reef in the Florida Keys, USA. Coral Reefs 25:287-295

Hoyt WD (1927) The periodic fruiting of Dictyota and its relation to the environment. Am J Bot 14:592-619

> Hughes TP (1994) Catastrophes, phase shifts, and large-scale degradation of a Caribbean coral reef. Science 265: $1547-1551$

Hughes TP, Tanner JE (2000) Recruitment failure, life histories and long-term decline of Caribbean corals. Ecology 81:2250-2263

Hughes TP, Bellwood DR, Folke C, McCook LJ, Pandolfi JM (2007a) No-take areas, herbivory and coral reef resilience. Trends Ecol Evol 22:1-3

Hughes TP, Rodrigues MJ, Bellwood DR, Ceccarelli DM and others (2007b) Phase shifts, herbivory, and the resilience of coral reefs to climate change. Curr Biol 17:360-365

> Jompa J, McCook LJ (2002a) Effects of competition and herbivory on interactions between a hard coral and a brown alga. J Exp Mar Biol Ecol 271:25-39

Jompa J, McCook LJ (2002b) The effects of nutrients and her- bivory on competition between a hard coral (Porites cylindrica) and a brown alga (Lobophora variegata). Limnol Oceanogr 47:527-534

Jompa J, McCook LJ (2003) Coral-algal competition: macroalgae with different properties have different effects on corals. Mar Ecol Prog Ser 258:87-95

Koltes K, Tschirky J, Feller IC (1998) Carrie Bow Cay, Belize. In: Kjerfve B (ed) Caricomp - Caribbean coral reef, seagrass and mangrove sites. Coastal Region and Small Islands Papers 3, UNESCO, Paris, p 79-94

Lapointe BE, Littler MM, Littler DS (1997) Macroalgal overgrowth of fringing coral reefs at discovery bay, Jamaica: bottom-up versus top-down control. Proc 8th Int Coral Reef Symp, Panama 1:927-932

- Lapointe BE, Barile PJ, Matzie WR (2004) Anthropogenic nutrient enrichment of seagrass and coral reef communities in the lower Florida keys: discrimination of local versus regional nitrogen sources. J Exp Mar Biol Ecol 308: 23-58

Leslie PH (1945) On the use of matrices in certain population mathematics. Biometrika 35:213-245

> Lessios HA, Garrido MJ, Kessing BD (2001) Demographic history of Diadema antillarum, a keystone herbivore on Caribbean reefs. Proc R Soc Lond B Biol Sci 268:2347-2353

- Lewis IF (1910) Periodicity in Dictyota at Naples. Bot Gaz 50:59-64

- Lewis SM (1986) The role of herbivorous fishes in the organization of a Caribbean reef community. Ecol Monogr 56: $183-200$

- Lewis SM, Norris JN, Searles RB (1987) The regulation of morphological plasticity in tropical reef algae by herbivory. Ecology 68:636-641

Lirman D (2001) Competition between macroalgae and corals: effects of herbivore exclusion and increased algal biomass on coral survivorship and growth. Coral Reefs 19:392-399

> Lirman D, Biber PD (2000) Seasonal dynamics of macroalgal communities of the northern Florida reef tract. Bot Mar 43:305-314

Littler DS, Littler MM (2000) Caribbean reef plants. OffShore Graphics Inc., Washington, DC

Littler MM, Littler DS, Lapointe BE (1992) Modification of tropical reef community structure due to cultural eutrophication: the southwest coast of Martinique. Proc 7 th Int Coral Reef Symp, Guam 1:335-343

- McClanahan TR (1997) Primary succession of coral reef algae: differing patterns on fished versus unfished reefs. J Exp Mar Biol Ecol 218:77-102

McClanahan TR, Muthiga NA (1998) An ecological shift in a remote coral atoll of Belize over 25 years. Environ Conserv 25:122-130

> McClanahan TR, Kamukuru AT, Muthinga NA, Gilagabher Yebio M, Obura D (1996) Effects of sea urchin reductions on algae, coral and fish populations. Conserv Biol 10:136-154

McClanahan TR, Sala E, Mumby PJ, Jones S (2004) Phosphorus and nitrogen enrichment do not enhance brown frondose 'macroalgae'. Mar Pollut Bull 48:196-199

Miller MW, Hay ME (1996) Coral seaweed grazer nutrient interactions on temperate reefs. Ecol Monogr 66:323-344

Moloney KA (1986) A generalized algorithm for determining category size. Oecologia 69:176-180

> Mumby PJ (2006) The impact of exploiting grazers (Scaridae) on the dynamics of Caribbean coral reefs. Ecol Appl 16: 747-769

Mumby PJ, Foster NL, Glynn Fahy EA (2005) Patch dynamics of coral reef macroalgae under chronic and acute disturbance. Coral Reefs 24:681-692 
Mumby PJ, Harborne AR, Williams J, Kappel CV and others (2007) Trophic cascade facilitates coral recruitment in a marine reserve. Proc Natl Acad Sci USA 104:8362-8367

> Neto AI (2000) Observations on the biology and ecology of selected macroalgae from the littoral of Sao Miguel (Azores). Bot Mar 43:483-498

Norton TA, Mathieson AC, Neushul M (1982) A review of some aspects of form and function in seaweeds. Bot Mar 25:501-510

Nugues MM, Bak RPM (2006) Differential competitive abilities between Caribbean coral species and a brown alga: a year of experiments and a long-term perspective. Mar Ecol Prog Ser 315:75-86

Paul VJ, Hay ME (1986) Seaweed susceptibility to herbivory: chemical and morphological correlates. Mar Ecol Prog Ser 33:255-264

Peckol P, Searles RB (1984) Temporal and spatial patterns of growth and survival of invertebrate and algal populations of a North Carolina continental shelf community. Estuar Coast Shelf Sci 18:133-143

Pinheiro JC, Bates DM (2000) Mixed-effects models in s and

Editorial responsibility: Tim McClanahan, Mombasa, Kenya s-plus. Springer-Verlag, New York

Quan-Young LI, Diaz-Martin MA, Espinoza-Avalos J (2004) Floristics, cover, and phenology of marine macroalgae from Bajo Pepito, Isla Mujeres, Mexican Caribbean. Bull Mar Sci 75:11-25

- Richardson JP (1979) Overwintering of Dictyota dichotoma (Phaeophyceae) near its northern distribution limit on the east coast of North America. J Phycol 15:22-26

Sauer JR, Slade NA (1987) Size-based demography of vertebrates. Annu Rev Ecol Syst 18:71-90

Steneck RS, Dethier MN (1994) A functional group approach to the structure of algal-dominated communities. Oikos 69:476-498

Tanner JE (1995) Competition between scleractinian corals and macroalgae: an experimental investigation of coral growth, survival and reproduction. J Exp Mar Biol Ecol 190:151-168

Vandermeer J (1978) Choosing category size in a stage projection matrix. Oecologia 32:79-84

> Weil E, Smith G, Gil-Agudelo DL (2006) Status and progress in coral reef disease research. Dis Aquat Org 69:1-7

Submitted: March 2, 2009; Accepted: November 27, 2009

Proofs received from author(s): March 11, 2010 